\title{
The Yo-Yo IR2 test in professional basketball players
}

\author{
Veli Volkan Gürses ${ }^{1}$ \\ Mustafa Şakir Akgül ${ }^{2}$ \\ Bayram Ceylan ${ }^{3}$ \\ Bilgehan Baydil ${ }^{4}$
}

\begin{abstract}
The aim of this study was to investigate the relationship between direct method and indirect method (Yo-Yo Intermittent Recovery Test Level II) that are used to determine aerobic capacity and endurance. Fourteen basketball players (22.49 \pm 04.82 year-old with the height $192.36 \pm 5.90$ $\mathrm{cm}$, weight $89.21 \pm 7.6 \mathrm{~kg}$, Body fat percentage $11.07 \pm 1.82 \%$ ) voluntarily participated in this study. Yo-Yo Intermittent Recovery Test Level II protocol (YIRT 2) was implemented to participants. Distance covered by the athletes, estimated $\mathrm{VO}_{2 \max }$, direct $\mathrm{VO}_{2 \max }$, Anaerobic threshold $\mathrm{VO}_{2 \text { and }}$ Anaerobic threshold heart rate $\left(\mathrm{HR}_{\mathrm{AT}}\right)$ values were recorded. Direct $\mathrm{VO}_{2 \max }$ and other respiratory parameters were measured with telemetric gas analyzer. After 5 minute rest in supine position heart rates $\left(\mathrm{HR}_{\text {rest }}\right)$, rest lactate levels $\left(\mathrm{LA}_{\text {rest }}\right)$ and maximal heart rate $\left(\mathrm{HR}_{\max }\right)$ during the test and post test lactate levels $\left(\mathrm{LA}_{\mathrm{poss}}\right)$ were measured. Pearson Correlation Test was used to determine the relationship between the variables. $\mathrm{P}$ value was set at 0,05 . According to the findings, positively significant large correlation was found between estimated $\mathrm{VO}_{2 \max }$ and direct $\mathrm{VO}_{2 \max }(\mathrm{r}=0.504, \mathrm{p}<0.05), \mathrm{HR}_{\max }(\mathrm{r}=0.501, \mathrm{p}<0.05)$, positively significant large correlation was found between distance and Direct $\mathrm{VO}_{2 \max }(\mathrm{r}=0.521, \mathrm{p}<0.05), \mathrm{HR}_{\max }(\mathrm{r}=0.516, \mathrm{p}<0.05)$. There is no significant relationship except above-mentioned variables $(\mathrm{p}<0.05)$. YIRT2 can guess $\mathrm{VO}_{2 \max }$ of professional male basketball players and can be used to evaluate endurance.
\end{abstract}

Keywords: Aerobic capacity; Endurance tests; Yo-Yo Intermittent Recovery Test; $\mathrm{VO}_{2 \max }$, Basketball.

\section{Introduction}

Many laboratory and field testing protocols have been developed to evaluate aerobic capacity and endurance. Laboratory tests are the most effective ways to determine aerobic capacity with more accuracy and accepted as golden standard (Atkins, 2006; Lager and Lambert, 1982). However, these protocols require expensive equipments and their applications take too much time for team sports. In this sense, coaches of team sports prefer field testing protocols whose validity and reliability were confirmed in order to evaluate their athletes. Field testing protocols provide team

\footnotetext{
${ }^{1}$ Phd. Assistant Professor, Kastamonu University, School of Physical Education and Sport, vgurses@kastamonu.edu.tr 2Phd. Assistant Professor, Kastamonu University, School of Physical Education and Sport,msakgul@,kastamonu.edu.tr 3Research Assistant, Kastamonu University, School of Physical Education and Sport, bceylan@kastamonu.edu.tr

4Phd. Associated Professor, Kastamonu University, School of Physical Education and Sport, bilgehan@kastamonu.edu.tr
} 
Gürses, V. V., Akgül, M. Ş.,Ceylan, B.,\&Baydil, B. (2018). The Yo-Yo IR2 test in professional basketball players. Journal of Human Sciences, 15(1), 368-374. doi:10.14687/jhs.v15i1.5226

coaches with physical fitness of the athletes with minimal cost and time (Bangsbo et al., 2008; Gürses et. al., 2017). Field testing protocols are generally based on increasing load (Aziz et al., 2005; Mayorga et al.,2015). In contrast, many team sports are based upon intermittent load. In order to solve this problem, Bangsbo (1994) developed Yo-Yo Intermittent Recovery Test I (YIRT1) and Yo-Yo Intermittent Recovery Test II (YIRT2) protocols by using 20m Shuttle Run Test.

YIRT1 was adapted according to physical and physiologic structures of team sports (Bangsbo et al., 2008). Strong relationships were found in the literature between direct $\mathrm{VO}_{2 \max }$ and YIRT (Bangsbo et al., 2008; Castagna et al., 2009). YIRT1 is applied to non-elite, recreational athletes while YIRT2 is used for elite athletes (Krustrup et al.,2003). Significant very large correlation $(\mathrm{r}=0.77)$ was found between YIRT1 and $\mathrm{VO}_{2 \max }$ of basketball players (Castanga et al., 2008). Nevertheless, there is no enough result reported about YIRT2 and basketball (Can and Cihan, 2013). Despite all, YIRT2 protocol was stated to be an effective measurement tool for elite basketball players (Bangsboo et al. 2008).

Basketball is a team sport where mostly aerobic energy pathway is used (Castagna et al., 2008; McInnes et al., 1995). The importance of aerobic capacity is explained with game duration, total match action numbers and distance covered by the athletes (Gürses et. al., 2017). Previous studies suggested match duration as 90-105 minutes and total action numbers as 997-1103 (Abdelkrimet al., 2007; Bishop and Wright, 2006; McInnes et al., 1995). Additionally, mean distance covered by the athletes during a match ranged from 6390 to $7558 \mathrm{~m}$ (Abdelkrim et al., 2007; Leite et al., 2013). During a match, basketball players intensely present abilities requiring strength, velocity, high level technique and tactic (Abdelkrim et al, 2009). Success depends mostly on these activities. Previous studies determined that high intensity activities are carried out 105193 times during a match (Abdelkrim et al., 2010; McInnes et al., 1995). High intensity activity lasting from 2 to 6 seconds is repeated every 30 seconds (Bishop and Wright, 2006). In the light of such information, it can be said that energy demanded for these activities is provided from ATPCP and anaerobic glycolysis pathways (Apostolidis et al. 2004). However, after a short period of the match repeated activities without enough recovery time lead to ATP deficiency (Abdelkrim et al., 2009; Bangsbo et al., 2008). In this sense, covering the ATP deficiency relies mostly on high oxygen consumption (Bognadis et al., 1996). In other words, maximal oxygen consumption $\left(\mathrm{VO}_{2 \max }\right)$ is an important factor for success in basketball. It is stated that aerobic capacity is very important for basketball performance and plays an important and active role in ATP reproduction periods (Apostolidis et al., 2004; Helgerud et al., 2001). Because YIRT2 is based on increasing and intermittent load protocol, it evaluates the ability to recover between high intensity intermittent exercises (Bangsboo et al., 2008). Thus, the aim of this study was to determine the relationship between direct method and YIRT2 that are used to determine aerobic capacity and endurance.

\section{Material and Method \\ Participants}

Fourteen male professional basketball players (22.49 \pm 04.82 year-old with the height $192.36 \pm 5.90 \mathrm{~cm}$, weight $89.21 \pm 7.6 \mathrm{~kg}$, body fat percentage $11.07 \pm 1.82 \%$ ) voluntarily participated in this study.

\section{Experimental Approach}

Measurements were carried out at the end of the season. 7 days before the first measurement familiarization was carried out with telemetric oxygen analyzer. Participations were told to refrain from any strenuous physical activities during 72 hours prior to the measurements. Measurements were carried out on the hardwood floor in a sport hall between 10.00-12.00 and 16.00-18.00 hours of the day. Before the tests, the floor was cleaned. Tests were implemented between $20-25 \mathrm{C}^{\circ}$ and $54-65 \%$ relative humidity. When the participants came to the sport hall, firstly anthropometric measurements were carried out and then they rested for five minutes in supine position to record 
Gürses, V. V., Akgül, M. Ş.,Ceylan, B.,\&Baydil, B. (2018). The Yo-Yo IR2 test in professional basketball players. Journal of Human Sciences, 15(1), 368-374. doi:10.14687/jhs.v15i1.5226

$\mathrm{HR}_{\text {rest }}$ and $\mathrm{LA}_{\text {rest }}$ values. The participants individually warmed up for 15 minutes. Following the warm-up, the participants were equipped with telemetric oxygen analyzer and tested. Verbalencouragement was provided during the whole test. In the $1^{\text {st }}$ minute after the test $L A_{\text {post }}$ levels were measured. Distance covered by the athletes, estimated $\mathrm{VO}_{2 \max }$, direct $\mathrm{VO}_{2 \max }$, Anaerobic threshold $\mathrm{VO}_{2}$, Anaerobic threshold heart rate $\left(\mathrm{HR}_{\mathrm{AT}}\right)$, and maximal heart rate $\left(\mathrm{HR}_{\max }\right)$ values were recorded.

\section{Anthropometric measurements}

Height, body mass and body fat percentage measurements were performed when participants came to the sport hall. Heights of the participants were measured with stadiometer (SECA, Germany) in centimeter with $1 \mathrm{~cm}$ sensibility. Body mass and body fat percentage were measured with segmental body composition analyzer (AVIS 333 Plus Body Composition Analyzer, Korea) in kilogram and percentage, respectively.

\section{Yo-Yo Intermittent Recovery Test Level 2}

Yo-Yo test protocols were developed in accordance with physical and physiological structures of team sports (Bangsbo et al., 2008; Castagna et al., 2009). These tests are inspired by $20 \mathrm{~m}$ Shuttle Run Test (20m SRT). 10-second active recovery following a $40 \mathrm{~m}$ run is distinctive element of YIRTs from 20m SRT. YIRT2 is developed for elite-level athletes (Krustrup et al. 2003). Test was implemented by preparing a 20-meter running area marked with lines and recovery area 5 meters from the beginning point. The participants started running with a speed of $13 \mathrm{~km} / \mathrm{h}$ and running speed was intermittently increased as suggested by Bangsbo et al. (2008). When participants could not cover $40 \mathrm{~m}$ distance in accordance with the signal and repeated this consecutively the test was ended and the distance was recorded as test performance. Estimated $\mathrm{VO}_{2 \max }$ of the participants was calculated according to the formula suggested by Bangsbo et al. (2008).

\section{Ventilation parameters}

Telemetric automatic gas analyzer system (Jaeger Oxycon Mobile, Germany) was used to measure ventilation parameters for specifying aerobic capacity at golden standard. The device was calibrated as suggested by the producer and 5 seconds cycle was used in "breath by breath" mode. Three criteria were used to evaluate $\mathrm{VO}_{2 \max }$ of the participants; a plateau in $\mathrm{VO}_{2}$ despite increasing speed, a RER value higher than 1.10 and a higher HR $( \pm 10)$ than $95 \%$ of calculated HR with 220 age formula. Mean of the highest 3 values when at least one of the above-mentioned criteria happened were used to calculate $\mathrm{VO}_{2 \max }$ (Howley et al., 1995).

\section{Blood lactate levels}

The blood lactate levels were determined by using lancing with drilling at the distal phalanx of the index finger (Accutrend plus GCTL with reagent strips BM-Lactate, Roche, Germany). Before collecting samples, participants' toes were cleaned with cotton soaked in alcohol $90^{\circ}$ and dried well and then $\sim 25 \mu$ l of blood was collected. The blood sample was placed directly on the test strips for the lactate measurement by using the same drill.

\section{Determining heart rates}

A short-range telemetric heart rate monitor (S 810, Polar Electro Oy, Kempele, Finland) was placed on the player approximately 20 min before testing. The heart rate was monitored throughout the test, using a $5 \mathrm{~s}$ interval recording time. Post-hoc HR analyses were performed using Polar Precision System SW software (Polar Electro Oy, Kempele, Finland). 
Gürses, V. V., Akgül, M. Ş.,Ceylan, B.,\&Baydil, B. (2018). The Yo-Yo IR2 test in professional basketball players. Journal of Human Sciences, 15(1), 368-374. doi:10.14687/jhs.v15i1.5226

\section{Statistics}

The data was analyzed with SPSS 22. Descriptive statistics were used to determine mean values and standard deviations of the all variables. Normality was determined with Shapiro Wilk test. The relationship between distance, estimated $\mathrm{VO}_{2 \max }$, direct $\mathrm{VO}_{2 \max }, \mathrm{VO}_{2 \mathrm{AT}}, \mathrm{HR}_{\mathrm{AT}}$ and $\mathrm{LA}_{\text {post }}$ values was determined with Pearson Correlation Test. Correlation coefficients were classified according to Hopkins (http://www.sportsci.org/resource/stats/effectmag.html). P value was set at 0.05 .

\section{Results}

Physical characteristics of the participants are presented in Table 1. YIRT2 performance results and physiological variables of the participants are presented in Table 2. Table 3 is presented correlations between estimated $\mathrm{VO}_{2 \max }$, YIRT distance and direct $\mathrm{VO}_{2 \max }, \mathrm{VO}_{2 \mathrm{AT}}, \mathrm{HR}_{\mathrm{AT}}$ and $\mathrm{LA}_{\text {post }}$ variables.

Table 1. Physical characteristics of the participants

\begin{tabular}{lll}
\hline Variables $(\mathbf{n}=\mathbf{1 4})$ & Mean & SD \\
\hline Age (year) & 22.49 & 4.82 \\
Height (cm) & 192.36 & 5.90 \\
Body mass (kg) & 89.21 & 7.61 \\
Body fat percentage (\%) & 11.07 & 1.82 \\
\hline
\end{tabular}

Table 2. YIRT2 results of the professional basketball players

\begin{tabular}{|c|c|c|c|c|}
\hline Variables $(n=14)$ & Mean & SD & Min. & Max. \\
\hline Distance (m) & 590,00 & 191,25 & 360 & 1160 \\
\hline Estimated $\mathrm{VO}_{2 \max }(\mathrm{ml} / \mathrm{kg} / \mathrm{min})$ & 53,38 & 2,60 & 50,20 & 61,07 \\
\hline $\mathrm{VO}_{2 \max }(\mathrm{ml} / \mathrm{kg} / \mathrm{min})$ & 47,59 & 4,86 & 38,95 & 57,75 \\
\hline $\mathrm{VO}_{2 \mathrm{AT}}(\mathrm{ml} / \mathrm{kg} / \mathrm{min})$ & 40,63 & 3,99 & 31,42 & 48,70 \\
\hline $\mathrm{HR}_{\mathrm{AT}}(\mathrm{bpm})$ & 169,77 & 6,06 & 160,00 & 182,00 \\
\hline $\mathbf{L A}_{\text {rest }}(\mathrm{mmol} / \mathrm{L})$ & 1,49 & 0,25 & 0,90 & 2,00 \\
\hline $\mathbf{L A}_{\text {post }}(\mathrm{mmol} / \mathrm{L})$ & 12,68 & 2,40 & 18,90 & 7,80 \\
\hline $\mathrm{HR}_{\mathrm{rest}}(\mathrm{bpm})$ & 61,50 & 7,99 & 50,00 & 76,00 \\
\hline$H_{R_{\max }}(\mathrm{bpm})$ & 179,90 & 6,27 & 170,00 & 189,00 \\
\hline
\end{tabular}

$\mathbf{V O}_{\text {2max: }}$ Maximal Oxygen Consumption, $\mathbf{V O}_{2 \mathrm{AT}}$ : Anaerobic Threshold Oxygen Consumption, $\mathbf{H R}_{\mathrm{AT} \text { :Anaerobic }}$ Threshold Heart Rate, $\mathbf{L A}_{\text {rest: }}$ Resting Blood Lactate, $\mathbf{L A}_{\text {post. }}$ Post Test Blood Lactate, $\mathbf{H R}_{\text {rest: }}$ Rest Heart Rate, $\mathbf{H R}_{\text {mas: }}$ Maximum Heart Rate

Table 3. Correlation between laboratory test and field testing protocols

\begin{tabular}{|c|c|c|c|c|c|}
\hline & $\begin{array}{l}\mathrm{VO}_{2 \max } \\
(\mathrm{ml} / \mathrm{kg} / \mathrm{min})\end{array}$ & $\begin{array}{l}\mathrm{VO}_{2 \mathrm{AT}} \\
(\mathrm{ml} / \mathrm{kg} / \mathrm{min})\end{array}$ & $\begin{array}{l}\mathbf{H R}_{\mathrm{AT}} \\
(\mathrm{bpm})\end{array}$ & $\mathbf{L A}_{\text {post }}(\mathrm{mmol} / \mathrm{L})$ & $\begin{array}{l}\mathbf{H R}_{\max } \\
(\mathrm{bpm})\end{array}$ \\
\hline $\begin{array}{l}\text { EstimatedVO }_{2 \max } \\
(\mathrm{ml} / \mathrm{kg} / \mathrm{min})\end{array}$ & $\begin{array}{l}\mathrm{r}=0.504, * \\
\mathrm{p}=0,004\end{array}$ & $\begin{array}{l}\mathrm{r}=0.258 \\
\mathrm{p}=0,102\end{array}$ & $\begin{array}{l}\mathrm{r}=0.194 \\
\mathrm{p}=0,177\end{array}$ & $\begin{array}{l}\mathrm{r}=0.060 \\
\mathrm{p}=0,382\end{array}$ & $\begin{array}{l}\mathrm{r}=0.501, * \\
\mathrm{p}=0,003\end{array}$ \\
\hline Distance (m) & $\begin{array}{l}r=0.521, * \\
p=0,003\end{array}$ & $\begin{array}{l}r=0.260 \\
p=0,100\end{array}$ & $\begin{array}{l}r=0.183 \\
p=0,191\end{array}$ & $\begin{array}{l}r=0.073 \\
p=0,357\end{array}$ & $\begin{array}{l}r=0.516, * \\
p=0,002\end{array}$ \\
\hline
\end{tabular}

$\mathbf{V O}_{2 \text { max: }}$ Maximal Oxygen Consumption, $\mathbf{V O}_{2 \mathrm{AT}}$ : Anaerobic Threshold Oxygen Consumption, $\mathbf{H R}_{\mathrm{AT}}$ :Anaerobic Threshold Heart Rate, ,LA $\mathbf{A}_{\text {post. }}$ Post Test Blood Lactate, $\mathbf{H R}_{\text {mas: }}$ Maximum Heart Rate

\section{Discussion and Conclusion}

The main finding of the present study was: significant large correlation was found between estimated $\mathrm{VO}_{2 \max }$ value obtained from YIRT2 and direct $\mathrm{VO}_{2 \max }(\mathrm{r}=0.504, \mathrm{p}=0.004)$ and YIRT2 performance and direct $\mathrm{VO}_{2 \max }(\mathrm{r}=0.521, \mathrm{p}=0.003)$.YIRT was developed to evaluate aerobic capacities of the football players with match-like loads (Krustrup et al., 2003). YIRT1 lead to maximal usage of aerobic system with intermittent loads while YIRT2 evaluates recovery ability 
Gürses, V. V., Akgül, M. Ş.,Ceylan, B.,\&Baydil, B. (2018). The Yo-Yo IR2 test in professional basketball players. Journal of Human Sciences, 15(1), 368-374. doi:10.14687/jhs.v15i1.5226

between repeated exercises at high intensity (Bangsboo et al., 2008). However, the most frequently asked question about this issue is whether YIRT2 can correctly estimate $\mathrm{VO}_{2 \max }$ in team sports. Basketball is structurally very similar to YIRT2 (Abdelkrim et al., 2007;2010; Bishop and Wright, 2006). However, there is not enough study related to YIRT2 and basketball players (Mohr and Krustrup., 2014). Rampinini et al. (2010) found only moderate relation between YIRT2 performance and direct $\mathrm{VO}_{2 \max }(\mathrm{r}=0.47)$. While Krustrup et al. (2006) found a significant large correlation $(\mathrm{r}=0.56)$ between YIRT2 performance and direct $\mathrm{VO}_{2 \max }$, Krustrup et al. (2014) found a significant very large correlation between YIRT2 pefrmance and direct $\mathrm{VO}_{2 \max }$ in untrained footballers $(r=0.77)$. In this sense, our study is in parallel with the findings of literature. However, interestingly Krustrup et al. (2014) stated statistically no significant correlation between YIRT2 and direct $\mathrm{VO}_{2 \max }$ in trained football players $(\mathrm{r}=0.30)$, which is in contrast with our study. Therefore, the results of the present study gains importance. The answer of the most frequently asked question can be that YIRT2 can estimate direct $\mathrm{VO}_{2 \max }$ of professional basketball players.

A significant large correlation $(\mathrm{r}=0.77)$ was found between $\mathrm{VO}_{2 \max }$ and YIRT1 distance in a study on basketball players (Castanga et al., 2008). Nevertheless, in a review study about YIRTs by Bangsbo et al., (2008) which included 141 subjects, a significant large correlation $(\mathrm{r}=0.70)$ was found between $\mathrm{VO}_{2 \max }$ and YIRT1 while large correlation was found for YIRT2 $(\mathrm{r}=0.58)$. Rampinini et al. (2010) found only large relation between YIRT1 performance and direct $\mathrm{VO}_{2 \max }$ $(r=0.74)$. According to the findings of Aslan et al., (2012) the YIRT1 correlation was found very $(\mathrm{r}=0.89)$. Large correlation was found between YIRT1 and YIRT2 in the previous studies (Fanchini et al., 2014; Ingebrigtsen et al., 2014; Mohr and Krustrup., 2014; Rampinini et al., 2010; Thomas et al., 2006). In this respect, the present study can provide an idea in terms of evaluating basketball players as there are no adequate studies about YIRT2 in the literature. Notwithstanding, there are studies stating that there is no relationship between $\mathrm{VO}_{2 \max }$ and distance in YIRT1 (Aziz et al., 2005). In general, our findings show similarity with those in the literature. However, Karakoc et al., (2012) did not find a significant correlation between YIRT1 and YIRT2. This was thought to result from number of the participants $(\mathrm{n}=12)$. Castanga et al. (2008) found significant large correlation between $\mathrm{VO}_{2 \max }$ and YIRT1 distance in a study applied to basketball players. The result of this study is the same as ours.

Athletes' $\mathrm{HR}_{\text {rest }}$ and $\mathrm{LA}_{\text {rest }}$ values were $61.50 \pm 7.99 \mathrm{bpm}$ and $1.49 \pm 0.25 \mathrm{mmol} / \mathrm{L}$, respectively. This suggests that athletes started the test in rested condition. Another important finding of this study was: there was a significant large correlation between $\mathrm{HR}_{\max }$, estimated $\mathrm{VO}_{2}$ and YIRT2 performance. Maximal heart rate value after the test was found lower than the estimated one (220-age \pm 10$)$. Accordingly, HR was found low at the end of YIRT2. HR during YIRT2 was found lower than that during YIRT1 (Ingebrigtsen et al., 2012). Negative correlation was observed between $\mathrm{HR}_{\max }$ obtained on a treadmill and YIRT2 performance (Krustrup, 2006). The result of the present study is different from above-mentioned studies.

Hermassi et al. (2015) recommended that correlations between physiological estimation of anaerobic tolerance such as anaerobic threshold and blood lactate level and YIRT2 should be examined. We questioned the correlation between $\operatorname{VO}_{2 A T}(\mathrm{ml} / \mathrm{kg} / \mathrm{min}), \mathrm{HR}_{\mathrm{AT}}(\mathrm{bpm})$ which are important components of endurance and YIRT2. However, any significant correlation was not found between YIRT2 and anaerobic threshold. As already known, transition zone to anaerobic energy pathway is an important criterion for endurance performance. Notwithstanding, as mentioned before, YIRT2 evaluates recovery ability between repeated exercises at high intensity (Bangsboo et al., 2008). This result supports the present hypothesis. Moreover, Castanga et al. (2008) similarly showed no correlation between anaerobic threshold and YIRT1. Moreover, post test lactate tolerance supports this matter. Lactate accumulation was stated to be very high for YIRT2 and this situation was explained with high utilization of muscle glycogen (Bangsbo 2008; Krustrup 2014). In the present study, peak lactate levels of the basketball players were similarly 
Gürses, V. V., Akgül, M. S..,Ceylan, B.,\&Baydil, B. (2018). The Yo-Yo IR2 test in professional basketball players. Journal of Human Sciences, 15(1), 368-374. doi:10.14687/jhs.v15i1.5226

found high. Krustrup et al. (2014) stated no relationship between peak lactate and YIRT2, which supports the findings of our study.

As a result, the most frequently asked question about this issue whether YIRTs can correctly estimate VO2max in team sports was answered. This test can be used to estimate $\mathrm{VO}_{2 \max }$ of basketball players with saving time. However, such components as anaerobic threshold and running economy should be taken into consideration when evaluating endurance. The limitation of the present study was the number of the subjects ( $\mathrm{n}=14)$; it should be increased in the following studies in order to obtain more accurate correlation results. Moreover, at least two exercises can be carried out for more accurate estimations.

\section{References}

Abdelkrim, N.B., Castagna, C., El Fazaa, S., Tabka, Z., \& El Ati, J. (2009). Blood metabolites during basketball competitions. The Journal of Strength \& Conditioning Research, 23:(3), 765-773.

Abdelkrim, N.B., Castagna, C., Jabri, I., Battikh, T., El Fazaa, S., \& El Ati, J. (2010). Activity profile and physiological requirements of junior elite basketball players in relation to aerobicanaerobic fitness. The Journal of Strength \& Conditioning Research, 24:(9), 2330-2342.

Abdelkrim, N.B., El Fazaa, S., \& El Ati, J. (2007). Time-motion analysis and physiological data of elite under-19-year-old basketball players during competition. British journal of sports medicine, 41:(2), 69-75.

Apostolidis, N., Nassis, G. P., Bolatoglou, T., \& Geladas, N. D. (2004). Physiological and technical characteristics of elite young basketball players. Journal of Sports Medicine and Physical Fitness, 44:(2), 157.

Aslan, E., Müniroğlu, S., Alemdaroğlu, U., \&Karakoç, B. (2012). Investıgation of The Performance Responses of Yo-Yo And Shuttle Run Tests with The Treadmill Run Test in Young Soccer Players. Pamukekale Journal of Sport Sciences, 3:(3),104-112.

Atkins, S.J. (2006). Performance of the Yo-Yo Intermittent Recovery Test by elite professional and semiprofessional rugby league players. The Journal of Strength \& Conditioning Research, 20:(1), 222-225.

Aziz, A.R., Tan, F.H., \&Teh, K. C. (2005). A pilot study comparing two field tests with the treadmill run test in soccer players. Journal of sports science \& medicine, 4:(2),105-112.

Bangsbo, J. (1994). Fitness training in football: a scientific approach. August Krogh Inst., University of Copenhagen.

Bangsbo, J., Iaia, F.M., \&Krustrup, P. (2008). The Yo-Yo intermittent recovery test. Sports medicine, 38:(1), 37-51.

Bishop, D.C., \& Wright, C. (2006). A time-motion analysis of professional basketball to determine the relationship between three activity profiles: high, medium and low intensity and the length of the time spent on court. International Journal of Performance Analysis in Sport, 6:(1), 130-139.

Bogdanis, G. C., Nevill, M. E., Boobis, L. H., \&Lakomy, H. K. (1996). Contribution of phosphocreatine and aerobic metabolism to energy supply during repeated sprint exercise. Journal of Applied Physiology, 80:(3), 876-884.

Can,ì. Cihan, H.

H. (2013).

Yo-Yo

aralıklıtoparlanmatestlerivesportifperformansüzerinegenelbirdeğerlendirme. Spormetre11(2),81-94.

Castagna, C., Chaouachi, A., Rampinini, E., Chamari, K., \&Impellizzeri, F. (2009). Aerobic and explosive power performance of elite Italian regional-level basketball players. The Journal of Strength \& Conditioning Research, 23:(7), 1982-1987.

Castagna, C., Impellizzeri, F. M., Rampinini, E., D’Ottavio, S., \&Manzi, V. (2008). The Yo-Yo intermittent recovery test in basketball players. Journal of Science and Medicine in Sport, 11(2), 202-208. 
Gürses, V. V., Akgül, M. Ş.,Ceylan, B.,\&Baydil, B. (2018). The Yo-Yo IR2 test in professional basketball players. Journal of Human Sciences, 15(1), 368-374. doi:10.14687/jhs.v15i1.5226

Fanchini, M., Castagna, C., Coutts, A.J., Schena, F., McCall, A., \&Impellizzeri, F.M. (2014). Are the Yo-Yo intermittent recovery test levels 1 and 2 both useful? Reliability, responsiveness and interchangeability in young soccer players. Journal of sports sciences, 32:(20),1950-1957.

Gürses, V. V., Oskouei, M. M., Iş1k, Ö., \& Ersöz, Y. (2017). Determine of heart rate response during official competition in junior girl basketball players Y1ldız kız basketbolcularda resmi müsabaka sırasında kalp atım hızı yanıtlarının belirlenmesi. Journal of Human Sciences, 14(2), 1397-1404.

Helgerud, J., Engen, L.C., Wisloff, U., \& Hoff, J. (2001). Aerobic endurance training improves soccer performance. Medicine and science in sports and exercise, 33(11), 1925-1931.

Hermassi, S., Aouadi, R., Khalifa, R., van den Tillaar, R., Shephard, R. J., \&Chelly, M. S. (2015). Relationships between the $Y_{0}-Y_{O}$ intermittent recovery test and anaerobic performance tests in adolescent handball players. Journal of human kinetics, 45(1), 197-205.

Howley, E.T., Bassett, D.R., \& Welch, H.G. (1995). Criteria for maximal oxygen uptake: review and commentary. Medicine \& Science in Sports \& Exercise, 27:(1) 1292-301.

Ingebrigtsen, J., Bendiksen, M., Randers, M. B., Castagna, C., Krustrup, P., \&Holtermann, A. (2012). Yo-Yo IR2 testing of elite and sub-elite soccer players: performance, heart rate response and correlations to other interval tests. Journal of sports sciences, 30(13), 13371345.

Ingebrigtsen, J., Brochmann, M., Castagna, C., Bradley, P.S., Ade, J., Krustrup, P., \&Holtermann, A. (2014). Relationships between field performance tests in high-level soccer players. The Journal of Strength \& Conditioning Research, 28:(4), 942-949.

Karakoç, B., Akalan, C., Alemdaroğlu, U., \&Arslan, E. (2012). The relationship between the yo-yo tests, anaerobic performance and aerobic performance in young soccer players. Journal of buman kinetics, 35:(1), 81-88.

Krustrup, P., Mohr, M., Amstrup, T., Rysgaard, T., Johansen, J., Steensberg, A., \&Bangsbo, J. (2003). The yo-yo intermittent recovery test: physiological response, reliability, and validity. Medicine and science in sports and exercise, 35:(4), 697-705.

Krustrup, P., Mohr, M., Nybo, L., Jensen, J. M., Nielsen, J. J., \&Bangsbo, J. (2006). The Yo-Yo IR2 test: physiological response, reliability, and application to elite soccer. Medicine \& Science in Sports \& Exercise, 38(9), 1666-1673.

Leger, L.A., \& Lambert, J. (1982). A maximal multistage 20-m shuttle run test to predict $\backslash$ dot VO2 max. European journal of applied physiology and occupational physiology, 49:(1), 1-12.

Leger, L. A., Mercier, D., Gadoury, C., \& Lambert, J. (1988). The multistage 20 metre shuttle run test for aerobic fitness. Journal of sports sciences, 6:(2), 93-101.

Leite, N., Coutinho, D., \&Sampaio, J. (2013). Effects of fatigue and time-out on physiological, time-motion indicators and in patterns of spatial organization of the teams in basketball. In Revista de psicología del deporte,22:(1),215-218.

Mayorga-Vega, D., Aguilar-Soto, P., \&Viciana, J. (2015). Criterion-related validity of the 20-m shuttle run test for estimating cardiorespiratory fitness: A meta-analysis, Journal of sports science \& medicine, 14:(3), 536-547.

McInnes, S.E., Carlson, J.S., Jones, C.J., \& McKenna, M.J. (1995). The physiological load imposed on basketball players during competition. Journal of sports sciences, 13:(5), 387-397.

Mohr, M., \&Krustrup, P. (2014). Yo-Yo intermittent recovery test performances within an entire football league during a full season. Journal of sports sciences, 32:(4), 315-327.

Rampinini, E., Sassi, A., Azzalin, A., Castagna, C., Menaspà, P., Carlomagno, D., \&Impellizzeri, F.M. (2010). Physiological determinants of Yo-Yo intermittent recovery tests in male soccer players. European Journal of Applied Physiology, 108:(2), 401-409.

Thomas, A., Dawson, B., \& Goodman, C. (2006). The yo-yo test: reliability and association with a 20-m shuttle run and VO2max. International Journal of Sports Physiology and Performance, 1:(2), 137-149. 